\title{
Crescimento vegetativo de morangueiro através do uso de promotores de crescimento
}

\section{Adrik Francis Richter ${ }^{1}$, Rodrigo Ferraz $\operatorname{Ramos}^{2}$, Bruna Rohrig ${ }^{3}$, Jeferson Tonin ${ }^{4}$, Jose Tobias Marks Machado ${ }^{4}$}

\author{
${ }^{1}$ Universidade do Estado de Santa Catarina, Centro de Ciências Agroveterinárias, Lages, Santa Catarina, Brasil. E-mail: \\ adrikrichter@yahoo.com.br \\ ${ }^{2}$ Universidade Federal da Fronteira Sul, Campus Cerro Largo, Cerro Largo, Rio Grande do Sul, Brasil. E-mail: \\ rodrigoferrazramos@gmail.com \\ ${ }^{3}$ Universidade Federal de Pelotas, Campus Capão do Leão, Pelotas, Rio Grande do Sul, Brasil. E-mail: rohrigbruna@ hotmail.com \\ ${ }^{4}$ Universidade Federal do Rio Grande do Sul, Campus Agronomia, Porto Alegre, Rio Grande do Sul, Brasil. E-mail: \\ jeferson.tonin@hotmail.com, tobias.machado@hotmail.com
}

Recebido: 29/03/2018; Aceito: 03/04/2019.

\section{RESUMO}

O objetivo do presente trabalho foi avaliar os efeitos da inoculação individual e da coinoculação de Trichoderma e rizóbio, e a incorporação de silício, com e sem associação aos inoculantes, no crescimento vegetativo em mudas de morangueiro. $\mathrm{O}$ delineamento experimental foi em blocos casualizados, com oito tratamentos e quatro repetições, e duas plantas por repetição. As avaliações foram realizadas aos 22 e 55 dias após o transplantio. O tratamento com Trichoderma influenciou significativamente as variáveis 'diâmetro de coroa' e 'massa seca da coroa', enquanto o tratamento com aplicação de silício influenciou de forma significativa as variáveis 'área radicular', 'massa fresca de raiz', 'massa seca de raiz', 'massa fresca de trifólios' e 'massa fresca total da parte aérea'. As demais variáveis avaliadas não apresentaram diferença estatística para os diferentes tratamentos. Concluiu-se que o silício, quando coinoculado ou associado a outras inoculações, não exerceu influência significativa sobre as variáveis avaliadas, enquanto o Trichoderma influenciou no acúmulo de matéria na coroa, e a incorporação de Si apresentou-se como um elemento benéfico ao desenvolvimento vegetativo do morangueiro. Ainda, a variável 'área radicular' apresentou alta correlação com as demais variáveis.

Palavras-chave: Fragaria x ananassa Duch, Silício, Trichoderma, Rizóbio.

\section{Vegetative growth of strawberry through the use of growth promoters}

\section{ABSTRACT}

The objective of this study was to evaluate the effects of inoculation and co-inoculation of Trichoderma and rhizobia, and the incorporation of silicon, with and without the combination of the inoculants, on the vegetative growth in strawberry seedlings. The experimental design was carried out in randomized blocks, with treatments and four replicates, and two plants per replicate. They were found at 22 and 55 days after transplantation. The treatment with Trichoderma significantly influenced the variables 'crown diameter' and 'crown dry mass', while silicon treatment influenced the variables 'root area', 'fresh root mass', 'root dry mass', 'leaf fresh mass' and 'shoot fresh mass'. The different differences cannot be separated for different treatments. It was concluded that silicon, when inoculated or associated with other inoculations, did not have a great influence on the evaluated variables, whereas Trichoderma did not influence the accumulation of matter in the crown, and the incorporation of itself as a beneficial element to the vegetative development of the strawberry. Also, a "root" variable has a high frequency with the other variables.

Keywords: Fragaria x ananassa Duch, Silicon, Trichoderma, Rhizobium. 


\section{Introdução}

O morangueiro (Fragaria $\mathrm{x}$ ananassa Duch) pertence à família Rosaceae, que engloba grande número de espécies de clima temperado (Hancook e Luby, 1993; Sanhueza, 2005), sendo uma das espécies de maior expressão econômica entre as pequenas frutas, destacando-se pelo seu aspecto atraente e sabor agradável (Antunes et al., 2011; Madail et al., 2007). Apresenta alta rentabilidade, devido principalmente ao amplo conhecimento e aceitação da fruta pelo mercado consumidor e pela diversidade de opções de comercialização e processamento (Rigon et al., 2005; Fachinello et al., 2011).

$\mathrm{Na}$ busca de alternativas que possibilitem a obtenção de maior rentabilidade nas culturas agrícolas, novas tecnologias e estratégias estão sendo adotadas pelos agricultores, dentre eles, o uso de agentes biológicos e de componentes à base de Silício ( $\mathrm{Si}$ ) para incremento no crescimento e produção vegetal (Oliveira et al., 2013; Machado et al., 2012). Para a cultura do morangueiro, o uso de promotores de crescimento vegetal apresenta o potencial de melhoria no crescimento vegetativo (Serret-López et al., 2016; Figueiredo et al., 2010a).

Elementos minerais como o Silício (Si) também apresentam potencial de melhorar a qualidade físicoquímica dos frutos, bem como a arquitetura das plantas, fazendo com que essas desenvolvam folhas mais eretas, facilitando a interceptação dos raios solares e assim aumentando a taxa fotossintética (Figueiredo et al., 2010b; Silva et al., 2013). Assim, o uso de Si tem apresentado inúmeros benefícios para as plantas, incluindo aumento da produtividade e resistência contra pragas e doenças (Rodrigues et al., 2011). Ainda, o acúmulo de sílica na parede celular reduz a perda de água por transpiração, podendo ser um fator de adaptação ao estresse hídrico (Filgueiras, 2007; Ma e Yamaji, 2008).

Entre os promotores de crescimento vegetal, os microrganismos do grupo dos rizóbios, além de serem eficientes fixadores de nitrogênio, também são capazes de promover o crescimento de não-leguminosas por meio de diversos mecanismos, como a produção de hormônios (Chen et al., 2005; Schlindwein et al., 2008; Silva et al., 2017). Fungos do gênero Trichoderma são capazes de colonizar raízes de diversas espécies de plantas de interesse econômico, podendo estimular o crescimento vegetal (Bettiol et al., 2012; Stefanello e Bonett, 2013; Fragoso e Custódio, 2016). A colonização das raízes pode aumentar o desenvolvimento radicular, produtividade da cultura, resistência a estresses abióticos e melhoria do uso de nutrientes (Benítez et al., 2004).

Os efeitos benéficos de promotores de crescimento podem ser observados em plantas propagadas principalmente pelo aumento de área foliar, altura da planta, diâmetro do caule, número de folhas e matéria seca, redução do tempo de aclimatização, maior sobrevivência de mudas, controle de doenças e aumento de produtividade (Mariano et al., 2004).

O objetivo do presente trabalho foi avaliar o crescimento vegetativo em mudas de morangueiro submetidas a diferentes tratamentos biológicos com e sem a associação ao Silício.

\section{Material e Métodos}

Conduziu-se o experimento em sacos de polietileno da cor preta sobre bancadas em casa de vegetação, na Universidade Federal da Fronteira Sul (UFFS), Campus Cerro Largo/RS. Utilizou-se o cultivar Dover, realizando o desbaste da parte aérea e a uniformização das raízes através de corte transversal a sete centímetros da base da coroa. As mudas foram transplantadas em sacos de polietileno preto de $1000 \mathrm{~cm}^{3}$ preenchidos com substrato comercial Carolina Soil ${ }^{\circledR}$, composto à base de turfa Sphagno (70\%), palha de arroz torrefada (20\%) e perlita (10\%), pH 5,65, condutividade elétrica de 1,5 $\mathrm{dS} / \mathrm{m}$, densidade de $220 \mathrm{~kg} / \mathrm{m}^{3}$ (umidade 50\%), capacidade de retenção de água (CRA) $51 \%$ em volume, porosidade total de $76 \%$ e CTC de 1200 mmolc. dm ${ }^{-3}$.

Os inoculantes utilizados foram de origem comercial, espécie Trichoderma harzianum, com concentração $1,4 \times 10^{10}$ esporos $\mathrm{mL}^{-1}$, e o rizóbio da espécie Bradyrhizobium japonicum Semia 5079 e 5080, na concentração de 7,5 × $10^{9}$ células $\mathrm{mL}^{-1}$. Adotou-se também o uso de extrato mineral na forma de pó molhável (PM) da Gigamix ${ }^{\circledR}$, contendo $50 \%$ de $\mathrm{SiO}_{2}$, $4,5 \%$ de $\mathrm{P}_{2} \mathrm{O}_{5}, \quad 5,0 \%$ de $\mathrm{Ca}$ e $1,0 \%$ de $\mathrm{Mg}$, correspondente aos tratamentos com $\mathrm{Si}$.

A inoculação e a incorporação do Silício nos tratamentos foram realizadas três dias antes do transplantio, sendo aplicado em forma de calda diretamente no substrato. Nos tratamentos com Trichoderma, foram incorporados via seringa graduada $10 \mathrm{~mL}$ de calda por unidade experimental, na concentração de $0,4 \%$ (v/v) de inoculante. Nos tratamentos com rizóbio, foram incorporados via seringa graduada $10 \mathrm{ml}$ de calda por unidade experimental na concentração de $0,5 \%$ (v/v) de inoculante à base de Bradyrhizobium japonicum. Nos tratamentos com $\mathrm{Si}$, aplicou-se $10 \mathrm{~mL}$ de calda por unidade experimental a $15 \%(\mathrm{~m} / \mathrm{v})$ do extrato mineral. Para o tratamento testemunha, cada unidade experimental do tratamento recebeu $10 \mathrm{~mL}^{-1}$ de $\mathrm{H}_{2} \mathrm{O}_{\text {(liq) }}$ destilada via seringa graduada. Realizou-se fertirrigação de acordo com Schmitt et al. (2016).

O experimento foi conduzido utilizando delineamento em blocos casualizados, com oito (8) tratamentos e quatro (4) repetições, perfazendo um total 
de 32 parcelas. Cada parcela experimental foi composta por duas (2) plantas, totalizando 64 plantas. Os seguintes tratamentos foram adotados: T1: testemunha, recebeu somente água destilada; T2: inoculação apenas com Trichoderma; T3: inoculação apenas com rizóbio; T4: coinoculação de Trichoderma com rizóbio; T5: incorporação somente de silício; T6: incorporação de silício mais inoculação de Trichoderma; T7: incorporação de silício mais inoculação com rizóbio; T8: incorporação de silício mais coinoculação de bactérias do grupo rizóbio e Trichoderma.

Aos 22 e 55 dias após ao transplantio (DAT) foi determinado o número de trifólios (NT), realizando-se a contagem de trifólios plenamente abertos; a altura de planta (AP), medindo-se a distância entre a base da coroa até o ápice da última folha completamente expandida; e o diâmetro da coroa (DC), medindo-se o diâmetro da coroa ao nível do substrato com auxílio de paquímetro digital.

Aos 55 DAT, ocorreu a retirada das mudas dos sacos de polietileno, procedendo-se à lavagem em água corrente das raízes até a total retirada do substrato aderido. Realizou-se corte horizontal na base inferior e superior da coroa, separando-se em parte aérea, coroa e raízes. As raízes foram digitalizadas individualmente em um escâner multifuncional HP 1310 e determinada a área radicular (AR) através do Software ImageJ, através da técnica de binarização de imagens obtidas pelo escaneamento das imagens (Queiroz et al., 2013). Igualmente, a área foliar (AF) foi estimada aos 55 DAT através do escaneamento dos trifólios e submetida à análise no Software ImageJ.

Aos 55 DAT, após a retirada das mudas, foi realizada a mensuração da massa fresca de trifólios (MFT), massa fresca da coroa (MFC) e massa fresca da raiz (MFR) em balança analítica. Em sequência, as amostras foram acondicionadas em estufa de circulação de ar forçada a $75^{\circ} \mathrm{C}$ até atingir massa constante, e após a mensuração, obteve-se massa seca de trifólios (MST), massa seca da coroa (MSC) e massa seca da raiz (MSR).

Os dados obtidos foram submetidos à análise estatística pelo teste de Duncan a 5\% de probabilidade, utilizando o Sistema para Análise e Separação de Médias em Experimentos Agrícolas (SASM-Agri, versão 8.2 demo) (Canteri et al., 2001). Realizou-se a análise de correlações das variáveis pelo Sistema de Análise Estatística (Software S.A.S).

\section{Resultados e Discussão}

Para as variáveis 'altura de planta', 'número de trifólios' e 'área foliar' não ocorreu significância estatística (Tabela 1). Para a variável 'diâmetro de coroa' o tratamento com Trichoderma (T2) apresentou o maior diâmetro, apresentando diferença estatística entre os demais tratamentos (Tabela 1). Essa diferença no tratamento com Trichoderma pode ser decorrente da produção de fitohormônios, como a auxina, que é promotora de expansão celular e pode influenciar em um maior acúmulo de biomassa. Chagas Junior et al. (2014), avaliando o uso de Trichoderma em associação com Rizóbios em diferentes cultivares de feijão-caupi (Vigna unguiculata), observaram que a aplicação do Trichoderma, tanto em solo como em sementes, apresentou os melhores resultados para produção de biomassa e produtividade.

O tratamento com incorporação de silício (T5) apresentou as maiores médias para as variáveis 'área radicular', 'massa fresca' e 'massa seca' de raízes, diferindo estatisticamente dos demais tratamentos (Tabela 2). O Si pode atuar como um elemento benéfico, diminuindo a toxidez do alumínio nas raízes (Rodrigues et al., 2011). No solo, o Si pode competir com o fósforo pelos sítios de absorção nos óxidos de ferro e alumínio (Hingston et al., 1972), resultando em uma maior disponibilidade de fósforo para as raízes.

O tratamento com silício (T5) também apresentou as maiores médias para as variáveis 'massa fresca da parte aérea' e 'massa fresca total', diferindo estatisticamente dos demais tratamentos (Tabela 3). Contudo, para as variáveis 'massa seca da parte aérea' e 'massa seca total', o tratamento com Si não apresentou diferença estatística em relação aos demais tratamentos. Uma maior massa fresca no tratamento com $\mathrm{Si}$ pode ser consequência de um acúmulo de sílica na parede celular, que reduz a perda de água por transpiração (Filgueiras, 2007; Ma e Yamaji, 2008). Esse fator é importante para uma maior resiliência das plantas ao estresse hídrico (Rodrigues et al., 2011).

Para a variável 'massa seca da coroa', o tratamento com Trichoderma (T2) apresentou a maior média, diferindo estatisticamente dos demais tratamentos (Tabela 3). Esse resultado pode ser consequência da produção de hormônios vegetais (Machado et al., 2011), ou devido à disponibilização de fósforo via solubilização, gerando um acúmulo de reservas e o engrossamento da mesma (Gravel et al., 2007). Segundo Gomes e Paiva (2004), uma maior massa seca da parte aérea indica a rusticidade das mudas, influenciando a sobrevivência e o crescimento inicial em campo.

$\mathrm{Na}$ análise de correlação, observa-se a ocorrência de interferências entre as variáveis analisadas. Na cultura do morangueiro (Tabela 4), a variável 'área radicular' da planta pode interferir significativamente na 'altura da planta', bem como no 'diâmetro de coroa' e no acúmulo de 'massa fresca da parte aérea' e 'massa seca da parte aérea'. Francescangeli et al. (2006) concluíram que o maior crescimento vegetativo de plantas de morangueiro é positivo, pois está associado a taxas de crescimento 
mais elevadas da área foliar da cultura, a qual aumenta a quantidade de assimilados produzidos e estocados, melhorando assim a área fotossintética (Taiz e Zeiger, 2009).

Observa-se, na Tabela 4, que a variável 'área radicular' apresentou alta correlação com as variáveis 'massa fresca de raiz', 'massa seca de raiz', 'massa fresca da coroa' e 'massa fresca total da parte aérea'.
Ainda, a variável 'massa seca da raiz' apresentou alta correlação com as variáveis 'massa fresca' e 'massa seca de trifólios'. Os resultados indicam que um maior desenvolvimento radicular influencia positivamente no desenvolvimento vegetativo do morangueiro, como observado por Cocco et al. (2015), onde observaram correlação significativa entre a massa seca de raízes, massa seca da parte aérea e diâmetro da coroa.

Tabela 1. Altura de planta (AP), diâmetro de coroa (DC), número de trifólios (NT) e área foliar (AF) de morangueiro submetido a diferentes tratamentos biológicos com e sem associação ao silício.

\begin{tabular}{ccccc}
\hline Tratamento & $\begin{array}{c}\text { AP } \\
(\mathbf{m m})\end{array}$ & $\begin{array}{c}\text { DC } \\
(\mathbf{m m})\end{array}$ & $\mathbf{N T}$ & $\begin{array}{c}\text { AF } \\
\left(\mathbf{c m}^{2}\right)\end{array}$ \\
\hline T1 & $\mathbf{n s} 64,07$ & $9,99 \mathrm{~b}$ & $\mathbf{n s} 4,62$ & 53,80 \\
T2 & 74,13 & $12,44 \mathrm{a}$ & 5,37 & 93,34 \\
T3 & 67,04 & $12,09 \mathrm{ab}$ & 4,87 & 96,60 \\
T4 & 70,32 & $11,39 \mathrm{ab}$ & 4,75 & 90,19 \\
T5 & 73,85 & $11,44 \mathrm{ab}$ & 4,62 & 97,62 \\
T6 & 70,83 & $11,02 \mathrm{ab}$ & 57,29 \\
T7 & 71,01 & 5,0 & 100,76 \\
T8 & 68,95 & $11,09 \mathrm{ab}$ & 4,87 & 87,79 \\
\hline CV(\%) & 11,06 & 12,13 & 11,75 & 18,53 \\
\hline
\end{tabular}

Médias seguidas por mesma letra na coluna não diferem entre si pelo teste de Duncan, a $5 \%$ de probabilidade de erro. ${ }^{\text {ns: }}$ dados sem significância estatística. T1: testemunha; T2: Trichoderma; T3: rizóbio; T4: Trichoderma + rizóbio; T5: silício; T6: silício + Trichoderma; T7: silício + rizóbio; T8: silício + rizóbio + Trichoderma.

Tabela 2. Área radicular (AR), massa fresca da raiz (MFR) e massa seca da raiz (MSR) em morangueiro submetido a diferentes tratamentos biológicos com e sem incorporação de silício.

\begin{tabular}{cccc}
\hline Tratamento & $\begin{array}{c}\text { AR } \\
\left(\mathbf{c m}^{\mathbf{2}} \mathbf{\text { lanta }} \mathbf{- 1}\right)\end{array}$ & $\begin{array}{c}\text { MFR } \\
\left(\mathbf{g ~ p l a n t a}^{\mathbf{1}}\right)\end{array}$ & $\begin{array}{c}\text { MSR } \\
\mathbf{g ~ p l a n t a}^{\mathbf{- 1}} \mathbf{)}\end{array}$ \\
\hline T1 & $37,75 \mathrm{~b}$ & $3,59 \mathrm{~b}$ & $0,30 \mathrm{~b}$ \\
T2 & $50,45 \mathrm{ab}$ & $4,30 \mathrm{ab}$ & $0,40 \mathrm{ab}$ \\
T3 & $46,21 \mathrm{ab}$ & $4,48 \mathrm{ab}$ & $0,39 \mathrm{ab}$ \\
T4 & $44,20 \mathrm{ab}$ & $4,21 \mathrm{ab}$ & $0,38 \mathrm{ab}$ \\
T5 & $53,75 \mathrm{a}$ & $5,55 \mathrm{a}$ & $0,47 \mathrm{a}$ \\
T6 & $41,34 \mathrm{ab}$ & $4,40 \mathrm{ab}$ & $0,39 \mathrm{ab}$ \\
T7 & $42,60 \mathrm{ab}$ & $4,02 \mathrm{~b}$ & $0,37 \mathrm{ab}$ \\
T8 & $45,38 \mathrm{ab}$ & $4,09 \mathrm{~b}$ & $0,37 \mathrm{ab}$ \\
\hline CV(\%) & 20,84 & 19,73 & 21,42 \\
\hline
\end{tabular}

Médias seguidas por mesma letra na coluna não diferem entre si pelo teste de Duncan a $5 \%$. ns: Dados sem significância estatística. T1: testemunha; T2: Trichoderma; T3: rizóbio; T4: Trichoderma + rizóbio; T5: silício; T6: silício + Trichoderma; T7: silício + rizóbio; T8: silício + rizóbio + Trichoderma.

Tabela 3. Massa fresca de trifólios (MFT), massa seca de trifólios (MST), massa fresca da coroa (MFC), massa seca da coroa (MSC), massa fresca total da parte aérea (MFPA), massa seca total da parte aérea (MSPA) em morangueiro submetido a diferentes tratamentos biológicos, com e sem incorporação de silício.

\begin{tabular}{|c|c|c|c|c|c|c|}
\hline \multirow[b]{2}{*}{ Tratamento } & \multicolumn{2}{|c|}{ Trifólios } & \multicolumn{2}{|c|}{ Coroa } & \multicolumn{2}{|c|}{ Total da parte aérea } \\
\hline & $\begin{array}{c}\text { MFT } \\
\left(\text { g planta }^{-1}\right)\end{array}$ & $\begin{array}{c}\text { MST } \\
\left(\mathrm{g} \mathrm{planta}^{-1}\right)\end{array}$ & $\begin{array}{c}\text { MFC } \\
\left(\mathrm{g} \mathrm{planta}^{-1}\right)\end{array}$ & $\begin{array}{c}\text { MSC } \\
\left(\text { g planta }^{-1}\right)\end{array}$ & $\begin{array}{c}\text { MFPA } \\
\left(\mathrm{g} \mathrm{planta}^{-1}\right)\end{array}$ & $\begin{array}{c}\text { MSPA } \\
\left(\text { g planta }^{-1}\right)\end{array}$ \\
\hline T1 & $3,32 b$ & $\begin{array}{l}\text { ns } 0,48 \\
\end{array}$ & $\begin{array}{l}\text { ns } 0,52 \\
\text { ns }\end{array}$ & $0,15 b$ & $3,85 b$ & $\begin{array}{ll}\text { ns } 0,64 \\
\end{array}$ \\
\hline $\mathrm{T} 2$ & $4,19 \mathrm{ab}$ & 0,59 & 0,75 & $0,21 \mathrm{a}$ & $4,94 a b$ & 0,81 \\
\hline $\mathrm{T} 3$ & $4,67 \mathrm{ab}$ & 0,64 & 0,64 & $0,15 b$ & $5,13 \mathrm{ab}$ & 0,80 \\
\hline $\mathrm{T} 4$ & $3,94 \mathrm{ab}$ & 0,58 & 0,68 & $0,16 b$ & $4,64 a b$ & 0,75 \\
\hline T5 & $4,70^{\mathrm{a}}$ & 0,68 & 0,71 & $0,17 b$ & $5,41 \mathrm{a}$ & 0,85 \\
\hline T6 & $4,05 \mathrm{ab}$ & 0,55 & 0,56 & $0,13 b$ & $4,61 \mathrm{ab}$ & 0,69 \\
\hline $\mathrm{T} 7$ & $4,13 \mathrm{ab}$ & 0,62 & 0,62 & $0,14 b$ & $4,75 \mathrm{ab}$ & 0,77 \\
\hline $\mathrm{T} 8$ & $4,00 \mathrm{ab}$ & 0,55 & 0,66 & $0,15 b$ & $4,66 \mathrm{ab}$ & 0,64 \\
\hline $\mathrm{CV}(\%)$ & 19,69 & 21,59 & 21,51 & 14,82 & 17,21 & 18,27 \\
\hline
\end{tabular}

Médias seguidas por mesma letra na coluna não diferem entre si por teste de Duncan a $5 \%$. ns: Dados sem significância estatística. T1: testemunha; T2: Trichoderma; T3: rizóbio; T4: Trichoderma + rizóbio; T5: silício; T6: silício + Trichoderma; T7: silício + rizóbio; T8: silício + rizóbio + Trichoderma. 
Tabela 4. Análise de correlação das variáveis área radicular (AR), massa fresca radicular (MFR), massa seca radicular (MSR), altura de planta (AP), diâmetro de coroa (DC), número de trifólios (NT), área foliar (AF), massa fresca de trifólios (MFT), massa seca de trifólios (MST), massa fresca da coroa (MFC), massa seca da coroa (MSC), massa fresca total da parte aérea (MFPA) e massa seca total da parte aérea (MSPA) para mudas de morangueiro.

\begin{tabular}{|c|c|c|c|c|c|c|c|c|c|c|c|c|c|}
\hline Variável & $\mathbf{A R}$ & MFR & MSR & AP & DC & NT & $\mathbf{A F}$ & MFT & MST & MFC & MSC & MFPA & MSPA \\
\hline $\mathbf{A R}$ & & $0.82 * *$ & $0.88 * *$ & $0.75^{*}$ & $0.73^{*}$ & 0.29 & 0.56 & $0.79 *$ & $0.78 *$ & $0.89 * *$ & 0.66 & $0.88 * *$ & $0.78 *$ \\
\hline MFR & & & $0.95 * *$ & 0.63 & 0.47 & -0.17 & 0.50 & $0.82 * *$ & $0.80 *$ & 0.54 & 0.23 & $0.85^{* *}$ & $0.71 *$ \\
\hline MSR & & & & $0.80 *$ & 0.60 & 0.06 & 0.59 & $0.86^{* *}$ & $0.85 * *$ & $0.69 *$ & 0.33 & $0.92 * *$ & $0.77 *$ \\
\hline $\mathbf{A P}$ & & & & & 0.53 & 0.44 & 0.51 & 0.55 & 0.61 & $0.75 *$ & 0.52 & 0.69 & 0.65 \\
\hline DC & & & & & & 0.57 & 0.36 & 0.68 & 0.55 & $0.78 *$ & 0.65 & $0.72 *$ & 0.65 \\
\hline NT & & & & & & & 0.32 & 0.16 & 0.13 & 0.53 & 0.61 & 0.23 & 0.30 \\
\hline $\mathbf{A F}$ & & & & & & & & $0.76^{*}$ & $0.89 * *$ & 0.50 & 0.17 & $0.76^{*}$ & $0.82 * *$ \\
\hline MFT & & & & & & & & & $0.93 * *$ & 0.60 & 0.20 & $0.976^{* *}$ & $0.80 *$ \\
\hline MST & & & & & & & & & & 0.63 & 0.23 & $0.94 * *$ & $0.89 * *$ \\
\hline MFC & & & & & & & & & & & $0.77 *$ & $0.74 *$ & 0.69 \\
\hline MSC & & & & & & & & & & & & 0.33 & 0.54 \\
\hline MFPA & & & & & & & & & & & & & $0.84 * *$ \\
\hline MSPA & & & & & & & & & & & & & \\
\hline
\end{tabular}

Valores seguidos de dois asteriscos: considerados altamente significativos; valores seguidos de apenas um asterisco: considerados apenas significativo; valores sem o asterisco: não são considerados significativos pela análise de correlação feita pelo programa estatístico SAS.

No presente estudo, a variável 'diâmetro da coroa' está correlacionada com a 'massa fresca total da planta', ou seja, quanto maior o diâmetro da coroa, maior o acúmulo de biomassa da planta. Essa correlação pode ser resultado do fato de que a coroa apresenta a função de regular atividades metabólicas das plantas (Hancock, 1999). Também, segundo Han et al. (1993), a produtividade pode estar altamente relacionada ao diâmetro e número de coroas, podendo prever o potencial produtivo das plantas em função destas estruturas de reserva.

\section{Conclusões}

O $\mathrm{Si}$ proporcionou maior crescimento na 'área radicular', sendo que essa variável apresentou alta correlação com as demais variáveis. Esses resultados indicam que o uso de $\mathrm{Si}$ favorece o desenvolvimento radicular, que, por sua vez, influencia positivamente no desenvolvimento vegetativo do morangueiro. É indicada a incorporação do silício no substrato para o crescimento inicial de mudas de morangueiro.

O tratamento utilizando Trichoderma proporcionou maior acúmulo de matéria fresca na coroa, podendo ser utilizado no transplantio de mudas de morangueiro.

\section{Referências Bibliográficas}

Antunes, L.E.C., Carvalho, G.L., Santos, A.M., 2011. A cultura do morango, segunda ed. Embrapa Informação Tecnológica, Brasília.

Benítez, T., Rincón, A.M., Limón, M.C., Codón, A.C., 2004. Biocontrol mechanisms of Trichoderma strains. International Microbiology, 7(1), 249-260.
Bettiol, W., Morandi, M.A.B, Pinto, Z.V., Paula Junior, T.J., Correa, E.B., Moura, A.B., Lucon, C.M.M., Costa, J.C.B., Bezerra, J.L., 2012. Produtos Comerciais à Base de Agentes de Biocontrole de Doenças de Plantas. Embrapa Meio Ambiente, Jaguariuna.

Canteri, M.G., Althaus, R.A., Virgens Filho, J.S., Giglioti, E.A., Godoy, C.V., 2001. SASM - Agri: Sistema para análise e separação de médias em experimentos agrícolas pelos métodos Scoft - Knott, Tukey e Duncan. Revista Brasileira de Agrocomputação, 1(2), 18-24.

Chagas Junior, A.F., Oliveira, A.G., Reis, H.B., Santos, G.R., Chagas, L.F.B., Miller, L.O., 2014. Eficiência da inoculação combinada de rizóbio e Trichoderma spp. em diferentes cultivares de feijão-caupi (Vigna unguiculata) no cerrado (Savana Brasileira). Revista de Ciências Agrárias, 37(1), 2028.

Chen, X.C., Feng, J., Hou, B.H., Li, F.Q., Li, Q., Hong, G.F., 2005. Modulating DNA bending affects NodD-mediated transcriptional control in Rhizobium leguminosarum. Nucleic Acids Research, 33(1), 2540-2548.

Cocco, C., Gonçalvez, M.A., Picolotto, L.V.F., Antunes, L.E.C., 2015. Crescimento, desenvolvimento e produção de morangueiro a partir de mudas com diferentes volumes de torrão. Revista Brasileira de Fruticultura, 37(4), 961-969.

Fachinello, J.C., Pasa, M.S., Schmtiz, J.D., Betemps, D.L., 2011. Situação e perspectivas da fruticultura de clima temperado no Brasil. Revista Brasileira de Fruticultura, 33(esp.), 109-120.

Figueiredo, A.S.T, Resende, J.T.V, Silva, M.L.S., Meert, L., Kapp Neto, J., Dias, D.M., Zanin, D.S., Schwarz, K., Faria, M.V., 2010a. Produtividade do morangueiro em função de diferentes doses de silício aplicadas via solo e via foliar. Horticultura Brasileira, 29(2), 870-876.

Figueiredo, F.C., Botrel, P.P., Teixeira, C.P., Petrazzini, L.L., Locarno, M., Carvalho, J.G., 2010b. Pulverização foliar e fertirrigação com silício nos atributos físico-químicos de 
qualidade e índices de coloração do morango. Ciência e Agrotecnologia, 34(5), 1306-1311.

Filgueiras, O., 2007. Silício na agricultura. Pesquisa PAPESP, 140(1), 72-74.

Fragoso, D.B., Custódio, D.P., 2016. Uso de agentes de controle biológico e promotores de crescimento de plantas em arroz de terras altas. Fronteira Agrícola Informativo Técnico, 15(1), 1-3.

Francescangeli, N., Sangiacomo, M.A., Marti, H., 2006. Effects of plant density in broccoli on yield and radiation use efficiency. Scientia Horticulturae, 110(2), 135-143.

Gomes, J.M., Paiva, H.P., 2004. Viveiros florestais: propagação sexuada. UFV, Viçosa.

Gravel, V., Antoun, H., Tweddell, R.J., 2007. Growth stimulation and fruit yield improvement of greenhouse tomato plants by inoculation with Pseudomonas putida or Trichoderma atroviride: Possible role of índole acetic acid (IAA). Soil Biology \& Biochemistry, 39(8), 1968-1977.

Han, W., Kim, Y.D., Kang, S.G., Monn, J.S., Song, C.H., Chang, J.I., Park, Y.B., 1993. Studies on the establishment of hydroponics. 1. The effect of media on the quality and yield of strawberry in hydroponics. Journal of Agricultural Science Horticulture, 35(2), 401- 409.

Hancock, J.F., 1999. Strawberries. Cabi, Wallingford.

Hancook, J.F., Luby, J.J., 1993. Genetic resources a tour doorstep: the wild strawberries. Bio-science, 43(3), 141-147.

Hingston, F.J., Posner, A.M., Quirk, J.P., 1972. Anion adsorption by goethite and gibsite. I. The role of the proton in determining adsorption envelops. Journal of Soil Science, 23(1), 177-192.

Ma, J.F., Yamaji, N., 2008. Functions and transport of silicon in plants. Cellular and Molecular Life Sciences, 65(1), 30493057.

Machado, D.F.M., Parzianello, F.R., Silva, A.C.F., Antoniolli, Z.I., 2012. Trichoderma no Brasil: o fungo e o bioagente. Revista de Ciências Agrárias, 35(1), 274-288.

Machado, R.G., Sá, E.L.S., Damasceno, R.G., Hahn, L., Almeida, D., Moraes, T., Camargo, F.A.O., Reartes, D.S., 2011. Promoção de crescimento de Lotus corniculatus L. e Avena strigosa Schreb pela inoculação conjunta de Trichoderma harzianum e rizóbio. Ciência e Natura, 33(2), 111-126.

Madail, J.C.M., Antunes, L.E., Belarmino, L.C., Silva, B.A., Gardin, J.A., 2007. Avaliação econômica dos sistemas de produção de morango: convencional, integrado e orgânico. Embrapa Clima Temperado, Pelotas.

Mariano, R.L.R., Silveira, E.B., Assis, S.M.P., Gomes, A.M.A., Nascimento, A.R.P., Donato, V.M.T.S., 2004.
Importância de bactérias promotoras de crescimento e de biocontrole de doenças de plantas para uma agricultura sustentável. Anais da Academia Pernambucana de Ciência Agronômica, 1(1), 89-111.

Oliveira, J.T.L., Campos, V.B., Chaves, L.H.G., Guedes Filho, D.H., 2013. Crescimento de cultivares de girassol ornamental influenciado por doses de silício no solo. Revista Brasileira de Engenharia Agrícola e Ambiental, 17(2), 123-128.

Queiroz, J.E., Silva, G.H., Souza Neto, A.G., 2013. Avaliação estatística da área foliar através de modelos de equações em duas espécies florestais. Revista Verde de Agroecologia e Desenvolvimento Sustentável, 8(1), 146-153.

Rigon, L., Corrêa, S., Reetz, E., Vencato, A., Rosa, G.R., Beling, R.R., 2005. Pequenas frutas. Anuário Brasileiro da Fruticultura, 1(1), 90-97.

Rodrigues, F.A., Oliveira, L.A., Korndorfer, A.P., Kordorfer, G.H., 2011. Silício: um elemento benéfico e importante para as plantas. Informações Agronômicas, 134(1), 14-20.

Sanhueza, R.M.V., 2005. Sistema de produção de morango para mesa na região da serra gaúcha e encosta superior do Nordeste. Embrapa uva e vinho, Bento Gonçalves. https://sistemasdeproducao.cnptia.embrapa.br/FontesHTML/ Morango/MesaSerraGaucha/index.htm (acessado 09 de novembro de 2017).

Schlindwein, G., Vargas, L.K., Lisboa, B.B., Azambuja, A.C., Granada, C.E., Gabiatti, N.C., Prates, F., Stumpf, R., 2008. Influência da inoculação de rizóbios sobre a germinação e o vigor de plântulas de alface. Ciência Rural, 38(3), 658-664.

Schmitt, O.J., Andriolo, J.L., Schultz, E., Lerner, M.A., Souza, J.M., Picio, M.D., 2016. Produção de estolhos de cultivares de morangueiro em função da condutividade elétrica da solução nutritiva. Horticultura Brasileira, 34(2), 294-301.

Serret-López, M., Espinosa-Victoria, D., Gómez-Rodrígues, O., Delgadillo-Martínez, J., 2016. Tolerancia de plantas de fresa (Fragaria $x$ ananassa Duch.) premicorrizadas con Rhizophagus intraradices e inoculadas con PGPR's a Phytophthora capsici. Agrociencia, 50(8), 1107-1121.

Silva, E.R., Salles, J.S., Zuffo, A.M., Steiner, F., 2017. Coinoculação de Bradyrhizobium haponicum e Azospirillum brasilense em sementes de amendoim de diferentes tamanhos. Revista de Agricultura Neotropical, 4(5), 93-102.

Silva, M.L.S., Resende, J.T.V., Trevizam, A.R., Figueiredo, A.S.T., Schwarz, K., 2013. Influência do silício na produção e na qualidade de frutos do morangueiro. Semina: Ciências Agrárias, 34(6), 3411-3424.

Stefanello, L., Bonett, L.P., 2013. Avaliação do desenvolvimento de milho com Trichoderma spp. Revista Cultivando o Saber, 6(1), 121-127.

Taiz, L., Zeiger, E., 2009. Fisiologia vegetal, quarta ed. Artmed, Porto Alegre. 